\title{
QUALIDADE MICROBIOLÓGICA DE PIMENTA PRETA PRODUZIDA E COMERCIALIZADA EM SÃO MATEUS, ESPÍRITO SANTO, BRASIL
}

\author{
Alex Silva Lima ${ }^{1}$, Winy Galacho Baldan², Bruna Carminate ${ }^{3}$, Marcelo Barreto da \\ Silva $^{4}$, Maysa do Vale-Oliveira ${ }^{5}$ \\ ${ }^{1}$ Graduando em Agronomia pela Universidade Federal do Espírito Santo Campus \\ São Mateus, São Mateus-ES, Brasil. E-mail: alexlima010@yahoo.com.br \\ ${ }^{2}$ Mestranda em Agricultura Tropical pela Universidade Federal do Espírito Santo \\ Campus São Mateus, São Mateus-ES, Brasil. \\ ${ }^{3}$ Mestra em Agricultura Tropical pela Universidade Federal do Espírito Santo \\ Campus São Mateus, São Mateus-ES, Brasil. \\ ${ }^{4}$ Professor do curso de Agronomia na Universidade Federal do Espírito Santo \\ Campus São Mateus, São Mateus-ES, Brasil. \\ ${ }^{5}$ Professora adjunta na Universidade Federal do Espírito Santo Campus São Mateus, \\ São Mateus-ES, Brasil.
}

\section{Recebido em: 04/10/2019 - Aprovado em: 30/11/2019 - Publicado em: 15/12/2019 DOI: 10.18677/EnciBio_2019B46}

\begin{abstract}
RESUMO
A pimenta preta é um dos condimentos mais consumidos no mundo e o Brasil se destaca entre os maiores produtores e exportadores desta especiaria, sendo o estado do Espírito Santo o maior exportador do país. As etapas compreendidas entre a produção e o consumo podem ser fontes de contaminação microbiológica, reduzindo a qualidade do produto final e podendo inviabilizar sua utilização. $O$ trabalho objetivou identificar e quantificar possíveis microrganismos presentes em amostras de pimenta-do-reino provenientes de feira livre, mercado, supermercado e indústria exportadora no município de São Mateus - Espírito Santo. Todas as análises foram realizadas de acordo com o Compendium of methods for the microbiological examination of foods, foi utilizada a técnica de plaqueamento para detecção de microrganismos aeróbios mesófilos e bolores e leveduras, para detecção de Salmonella spp. foi utilizado o kit RapidChek SELECT Salmonella Test System e para detecção de coliformes foi utilizado o método dos tubos múltiplos. Os resultados encontrados mostraram que as amostras analisadas não estavam de acordo com a legislação vigente para microrganismos aeróbios mesófilos, bolores e leveduras e coliformes totais, identificando falhas na realização de boas práticas de fabricação, onde a presença desses microrganismos está associada à má higiene, processamento e armazenamento de forma inadequada gerando assim a contaminação do produto final.
\end{abstract}

PALAVRAS-CHAVE: higiene, microbiologia de alimentos, pimenta-do-reino. 


\title{
MICROBIOLOGICAL QUALITY OF BLACK PEPPER PRODUCED AND MARKETED IN SÃO MATEUS, ESPÍRITO SANTO, BRAZIL
}

\begin{abstract}
The black pepper is one of condiments more consumed in the world and Brazil if it detaches among the producing and exporting largers of this spice, being the state of Espírito Santo the second largest exporter in the country. The stages understood between the production and the consumption can be sources of microbiological contamination, reducing the final product quality and being able to make impracticable its use. The work objectified to identify and to quantify possible microrganismos gifts in samples of black pepper proceeding from free fair, market, supermarket and exporting industry in São Mateus - Espírito Santo. All the analyses had been carried through in accordance with the Compendium of methods for the microbiological examination of foods, were used the plating technique for detention of mesophilic aerobic microrganisms and mold and yeast, for detention of Salmonella spp. was used the kit RapidChek SELECT Salmonella Test System, for detention of coliforms was used the method of the multiple pipes. The results had shown that the analyzed samples were not in accordance with the legislation for mesophilic aerobic microorganisms, mold and yeast and total coliforms, identifying imperfections in the accomplishment of good practical of manufacture, where the presence of these microrganisms is associated with the bad hygiene, processing and storage of inadequate form thus generating the contamination of the end item.
\end{abstract}

KEYWORDS: higyene, food microbiology, black pepper.

\section{INTRODUÇÃO}

A pimenta-do-reino (Piper nigrum L.), conhecida internacionalmente como pimenta preta (black pepper), é uma das especiarias mais populares do mundo, largamente utilizada como condimento no preparo e processamento de alimentos, além de destacada importância nas indústrias de alimentos, fármacos, cosméticos e perfumarias devido ao elevado valor nutricional aliado a propriedades antioxidantes (OLIVEIRA et al., 2018). O cultivo adapta-se e cresce bem em diversos tipos de solo, com destaque aos solos profundos e que possuem boas condições de drenagem. Esses são fatores encontrados nas principais regiões produtoras do país, fazendo com que o Brasil esteja entre os maiores produtores e exportadores mundiais desta especiaria, (CARNEIRO JÚNIOR et al., 2017), gerando mais de 100 milhões de dólares ao país, com destacada importância econômica e social ao setor agropecuário (ANDRADE et al., 2017).

$\mathrm{O}$ consumidor tem se tornado cada vez mais exigente quanto à qualidade do produto que irá consumir, intensificando assim a preocupação de fazer uso de alimentos com melhores condições de higiene. Desse modo a avaliação da qualidade microbiológica dos alimentos e de seus ingredientes, inclusive os condimentos, é importante para identificar e quantificar diversos tipos de microrganismos que possam causar danos à saúde (LIMA et al., 2015; OLIVEIRA et al., 2016; OLIVEIRA et al., 2017).

A condição sanitária da pimenta preta é afetada principalmente durante o processo de secagem quando há presença de animais, pisoteio provocado por trabalhadores ou manuseio do produto sem higienização das mãos e se estende aos centros de distribuição como supermercados, restaurantes, mercados e feiras livres, 
onde a higienização dos alimentos deve seguir metodologia apropriada afim de garantir a segurança alimentar dos consumidores (LIMA et al., 2015).

Segundo Song et al. (2014) os microrganismos mais encontrados em pimentado-reino destacam-se bactérias do gênero Salmonella spp., coliformes totais e termotolerantes, microrganismos aeróbios mesófilos, Escherichia coli e Bacillus cereus. Bactérias do gênero Salmonella spp. são responsáveis por graves doenças de origem alimentar correspondendo por até $47 \%$ destas infecções. A presença desse microrganismo em alimentos se torna um grave problema de saúde pública, pois seus sintomas podem ser mal diagnosticados, apresentando diferentes sintomatologias como vômito, cólica, dor de cabeça, febre e diarreia, em decorrência da sua patogenicidade (WEBBER et al., 2019).

Segundo Franco e Landgraf (2008) aeróbios mesófilos apresentam crescimento entre $20^{\circ} \mathrm{C}$ e $45^{\circ} \mathrm{C}$ e seu monitoramento populacional reflete contaminação microbiana total, de forma que maiores valores estão relacionados à baixa qualidade sanitária de equipamentos e utensílios, enquanto que coliformes são bactérias da família Enterobacteriaceae, bacilos gram negativos e não formadores de esporos, capazes de fermentar a lactose com produção de gás e sua análise fornece com maior segurança informações sobre a condição de higiene do produto em questão.

Bolores e leveduras, de acordo com Alves et al. (2019) ocorrem principalmente em alimentos in natura ou minimamente processados, apresentando grande risco alimentar, pois algumas espécies produzem micotoxinas, compostos que ao serem ingeridos acumulam-se no organismo provocando sérios transtornos à saúde humana como ataques ao fígado e diversos tipos de câncer, além de modificar as características químicas e físicas dos alimentos.

Dada a importância dos padrões de qualidade dos alimentos, o trabalho objetivou avaliar a qualidade microbiológica de amostras de pimenta preta (Piper nigrum L.) produzidas e comercializadas no município de São Mateus, Espírito Santo, Brasil.

\section{Obtenção e preparo das amostras}

\section{MATERIAL E MÉTODOS}

O material utilizado na pesquisa foi coletado no período compreendido entre os meses de agosto a outubro de 2017, proveniente de diferentes locais de comercialização do produto, como mercado municipal, feiras livres e supermercados, além da coleta em local que realiza o processamento do produto, uma empresa exportadora de pimenta-do-reino. Todas os locais são situados do município de São Mateus, Espírito Santo, totalizando dezoito amostras. As amostras foram coletadas aleatoriamente no período da manhã, adquiridas de modo convencional representando de maneira fidedigna a condição real de como a pimenta preta é comercializada ao consumidor final. Estas foram acondicionadas em sacolas estéreis, a fim de evitar possíveis contaminações externas e encaminhadas ao laboratório de Fitopatologia e Análises Microbiológicas do Programa de PósGraduação em Agricultura Tropical da Universidade Federal do Espírito Santo Campus São Mateus, onde foram mantidas sob refrigeração até a realização dos procedimentos de análise.

Para realização das análises foram separadas 10 gramas de pimenta preta de cada amostra, adicionando posteriormente $90 \mathrm{~mL}$ de solução salina peptonada 
(concentração de $0,1 \%$ ). Em seguida procedeu agitação manual da solução para posterior diluição seriada decimal.

\section{Análises microbiológicas}

As análises foram realizadas de acordo com o Compendium of methods for the microbiological examination of foods (APHA, 2001). A contagem de microrganismos aeróbios mesófilos foi realizada por meio do método de plaqueamento em profundidade, que consiste em transferir $1,0 \mathrm{~mL}$ de cada diluição $\left(10^{-1}, 10^{-2}, 10^{-3}, 1^{-}\right.$ $4,10^{-5}$ ) para placas de petri previamente esterilizadas e adição de cerca de $15,0 \mathrm{~mL}$ de meio de cultura PCA (Ágar Padrão para Contagem) a temperatura de $45^{\circ} \mathrm{C}$ em cada placa semeada e homogeneização girando suavemente as placas no sentido horário e anti-horário alternadamente. Uma vez que o meio de cultura se solidificou, as placas foram invertidas e incubadas a $35^{\circ} \mathrm{C}$ durante 24 horas.

A contagem de bolores e leveduras foi realizada procedendo inoculação de alíquotas de cada diluição $\left(10^{-1}, 10^{-2}, 10^{-3}, 10^{-4}, 10^{-5}\right)$ em placas de Petri contendo meio de cultura BDA (Ágar Batata Dextrose) acidificado com ácido tartárico, espalhando uniformemente o conteúdo com alça Drigalsky, empregando duplicata e realizando inversão das placas. Após esse procedimento, as placas foram incubadas a $25^{\circ} \mathrm{C}$ por cinco dias.

$\mathrm{Na}$ contagem de coliformes totais e coliformes termotolerantes foi utilizado o método dos tubos múltiplos, com série de três tubos. Esse método consiste em transferir $1,0 \mathrm{~mL}$ de cada diluição para três tubos contendo meio lauril sulfato triptose (LST) e tubo de Durham invertido, seguido de incubação a $35^{\circ} \mathrm{C}$ por 48 horas. Após este período, procedeu-se com a separação dos tubos cujo resultado foi identificado como positivo, ou seja, turvos e com presença de gás no interior do tubo de Durham, transferindo-se uma alçada de cada tubo positivo de caldo LST para outro tubo contendo caldo E.C. e uma nova incubação a $45^{\circ} \mathrm{C}$ durante 24 horas com posterior identificação dos tubos positivos. Para quantificação do NMP (Número Mais Provável de coliformes termotolerantes por grama de alimento) utilizou-se a respectiva tabela. Selecionando-se um dos tubos contendo caldo E.C. cujo resultado positivo foi detectado, o conteúdo do mesmo foi semeado por estrias, de modo a obter colônias isoladas em ágar eosina azul de metileno (BEM), seguido de incubação a 35ํำ por 24 horas.

Para detecção de Salmonella spp. nas análises de pimenta-do-reino utilizou-se - kit RapidChek® SELECTTM Salmonella Food System (Romer Labs), sendo composto por materiais como Rapidchek SELECT meio primário, Rapidchek SELECT meio secundário e Rapidchek suplemento. Ao fim do período recomendado pelo fabricante, as amostras foram analisadas quanto à presença ou ausência de Salmonella spp. através da leitura da fita teste também fornecida pelo kit. Nessa leitura, o aparecimento de uma linha (controle) significa ausência do microrganismo e duas linhas a presença.

\section{RESULTADOS E DISCUSSÃO}

\section{Microrganismos aeróbios mesófilos}

Conforme a metodologia utilizada, os resultados encontrados em Unidade Formadora de Colônias (UFC)/g de alimento demonstraram que em todas as amostras de pimenta preta analisadas oriundas de feiras livres, mercado municipal, supermercados e indústria exportadora houve crescimento de aeróbios mesófilos. Os valores compreendidos entre $2,5 \times 10^{6}$ e $7,7 \times 10^{6}$ UFC/g correspondendo às 
amostras de feiras livres e mercado municipal, variação entre $1,4 \times 10^{3}$ a $6,0 \times 10^{6}$ $\mathrm{UFC} / \mathrm{g}$ nas amostras provenientes de supermercados e em amostras oriundas da indústria exportadora os valores se apresentaram entre $2,4 \times 10^{3}$ a $1,6 \times 10^{6}$, conforme apresentado na Tabela 1.

TABELA 1 - Microrganismos contaminantes presentes em amostras de pimenta-do- reino provenientes de diferentes locais de comercialização em São Mateus, Espírito Santo.

Amostra Contagem de microrganismos aeróbios mesófilos (UFC/g)

\begin{tabular}{|c|c|}
\hline \multicolumn{2}{|c|}{ Feiras livres e Mercado Municipal } \\
\hline $\begin{array}{c}1 \text { - Feiras } \\
2 \text { - Feiras } \\
3 \text { - Feiras } \\
4 \text { - Mercado } \\
5 \text { - Mercado } \\
6 \text { - Mercado }\end{array}$ & $\begin{array}{l}7,7 \times 10^{6} \\
4,2 \times 10^{6} \\
3,5 \times 10^{6} \\
2,5 \times 10^{6} \\
6,8 \times 10^{6} \\
6,5 \times 10^{6} \\
\end{array}$ \\
\hline $\begin{array}{l}1 \\
2 \\
3 \\
4 \\
5 \\
6\end{array}$ & $\begin{array}{l}7,3 \times 10^{3} \\
6,0 \times 10^{6} \\
4,5 \times 10^{3} \\
1,4 \times 10^{6} \\
6,0 \times 10^{3} \\
8,6 \times 10^{3}\end{array}$ \\
\hline $\begin{array}{l}1 \\
2 \\
3 \\
4 \\
5 \\
6\end{array}$ & $\begin{array}{l}2,7 \times 10^{3} \\
1,6 \times 10^{6} \\
1,4 \times 10^{6} \\
3,3 \times 10^{3} \\
2,6 \times 10^{3} \\
2,4 \times 10^{3}\end{array}$ \\
\hline
\end{tabular}

A legislação brasileira, na resolução RDC n¹2, de janeiro de 2001, da Agência Nacional de Vigilância Sanitária (ANVISA, 2001) não preconiza parâmetros para contagem em placas de microrganismos aeróbios mesófilos, porém a Compendium of methods for the microbiological examination of foods (APHA, 2001) estabelece um limite de $10^{4} \mathrm{UFC} / \mathrm{g}$. Nas análises realizadas com diferentes amostras de pimentado-reino, os resultados obtidos em relação às feiras livres e mercado municipal mostraram que $100 \%$ destas amostras apresentaram contagem elevada desse tipo de microrganismo, $30 \%$ das amostras oriundas de supermercados apresentaram contagem elevada $e$ as amostras provenientes da indústria exportadora corresponderam com 33,3\% das amostras apresentando contagem acima do limite.

A contagem de microrganismos aeróbios mesófilos não estabelece os tipos de bactérias e sua presença não está diretamente ligada à presença de patógenos ou toxinas. Porém a quantificação desta classe de microrganismos é adotada para avaliar as condições higiênico-sanitárias dos alimentos que podem ser afetadas por falhas durante as etapas de produção sendo: a manipulação, processamento, limpeza, armazenamento e transporte do alimento. Além disso, a avaliação da presença dessa classe de bactérias torna-se importante, pois, altas populações desses microrganismos em alimentos sugerem falhas na sanitização do local de produção (SILVA et al., 2010). 
Souza et al. (2015), em estudo que avaliou as condições de higiene do comércio de alimentos ao ar livre na cidade de Uberaba, Minas Gerais, identificaram que $76,7 \%$ das superfícies em contato direto com os alimentos apresentavam contagem de UFC superior ao recomendado. Esse resultado indica possíveis falhas nas práticas de limpeza e desinfecção do espaço, aliado ao fato de que estas superfícies não são constituídas de materiais passíveis de higienização, contribuindo para a proliferação de microrganismos contaminantes. Corroboram com estes, os resultados obtidos por Trindade et al. (2014) avaliando contaminação bacteriológica dos espaços de alimentação em escolas e creches em cidades do Vale do Jequitinhonha, em Minas Gerais, onde a alta carga microbiana encontrada nos variados utensílios utilizados indica deficiências nos processos de limpeza e sanitização, além da presença nas mãos dos profissionais responsáveis pela manipulação dos alimentos, sendo esta uma importante fonte de contaminação. Situação similar a encontrada nos espaços de feira livre e mercado municipal correspondentes a este trabalho, indicando a necessidade de aperfeiçoamento das boas práticas de higiene relacionadas a manipulação, armazenamento e exposição dos produtos nestes espaços.

\section{Bolores e leveduras}

Os resultados referentes as análises de bolores e leveduras apresentaram valores com variação entre $1,1 \times 10^{3}$ e $2,2 \times 10^{6} \mathrm{UFC} / \mathrm{g}$ de alimento em amostras de pimenta-do-reino comercializadas em feiras livres e mercado municipal. Amostras oriundas de supermercado apresentaram variação $1,0 \times 10^{3}$ a $4,4 \times 10^{6} \mathrm{UFC} / \mathrm{g}$ e quanto as amostras provenientes de indústria exportadora os valores se situaram entre $1,0 \times 10^{3}$ a $1,0 \times 10^{6}$, sendo estes apresentados na Tabela 2.

TABELA 2 - Colônias de bolores e leveduras presentes em amostras provenientes de diferentes locais de comercialização em São Mateus, Espírito Santo.

\begin{tabular}{cc}
\hline Amostra & Contagem de bolores e leveduras (UFC/g) \\
\hline & Feiras livres e Mercado Municipal \\
$7,7 \times 10^{6}$ & $4,2 \times 10^{6}$ \\
2 - Feiras & $3,5 \times 10^{6}$ \\
3 - Feiras & $2,5 \times 10^{6}$ \\
4 - Mercado & $6,8 \times 10^{6}$ \\
5 - Mercado & $6,5 \times 10^{6}$ \\
6 - Mercado & $7,3 \times 10^{3}$ \\
1 & $6,0 \times 10^{6}$ \\
2 & $4,5 \times 10^{3}$ \\
3 & $1,4 \times 10^{6}$ \\
4 & $6,0 \times 10^{3}$ \\
5 & $8,6 \times 10^{3}$ \\
\hline & Supermercados \\
2 & $2,7 \times 10^{3}$ \\
3 & $1,6 \times 10^{6}$ \\
4 & $1,4 \times 10^{6}$ \\
6 & $3,3 \times 10^{3}$ \\
\hline
\end{tabular}


De acordo com os critérios estabelecidos pela resolução RDC n¹2/2001, da Agência Nacional de Vigilância Sanitária (ANVISA, 2001), o limite para contaminação por bolores e leveduras em condimentos e especiarias é de $2 \times 10^{3}$ UFC/g. Os valores encontrados nesse trabalho mostraram que $83,3 \%$ das amostras comercializadas em feiras livres e no mercado municipal de São Mateus/ES não se encontram em conformidade com a legislação, pois apresentaram valores superiores ao permitido. Porcentagem menor em desconformidade com a legislação foi encontrada em amostras de supermercado, sendo que 66,6\% apresentaram contagem de UFC/g superior ao permitido. Para as amostras oriundas da indústria exportadora, $50 \%$ das amostras apresentação valores acima do estabelecido pela ANVISA.

Com relação à ocorrência dos maiores valores de colônias das amostras adquiridas de feiras livres e mercado é importante destacar que alguns fatores estão diretamente relacionados a esta situação dentre as quais as condições de higiene pessoal e das ferramentas e utensílios utilizados, dos recipientes para armazenamento, não cumprimento de boas práticas de manipulação, armazenamento em locais ou embalagens inapropriadas, favorecendo a ocorrência de contaminação (SOUZA et al., 2015; SILVA et al., 2018).

Resultados similares foram encontrados por Soares et al. (2017) analisando a qualidade de diferentes amostras de água de coco resfriada e extraída de forma manual por vendedores ambulantes na cidade de Mossoró, Rio Grande do Norte, Brasil, encontrando elevados valores durante a contagem de fungos e leveduras. Esse resultado indica possíveis falhas nas práticas de higienização dos utensílios e das mãos de manipuladores, representando um risco ao consumidor pela capacidade de produção de micotoxinas durante as atividades decompositoras destes microrganismos.

Santos et al. (2016) analisaram aspectos microbiológicos e físico-químicos de polpas de frutas comercializadas em Petrolina/PE e Juazeiro/BA. Esses autores mostraram a relação direta entre a contaminação por microrganismos e a higiene durante o processo de industrialização, e a influência desses fatores na qualidade inclusive sensorial dos produtos, visto que as polpas de frutas que apresentaram variação de sabores se destacaram pela alta contagem de microrganismos.

As amostras obtidas em supermercados, cujo processo de industrialização é realizado utilizando metodologias de controle de qualidade também apresentaram elevados valores de colônias de bolores e leveduras, indicando a necessidade de aperfeiçoamento das etapas e processos realizados desde a matéria-prima até a comercialização ao consumidor final. Em um estudo realizado por Oliveira et al. (2016) com o intuito de avaliar a contaminação fúngica em especiarias desidratadas comercializadas no mercado do porto de Cuiabá-MT, os resultados obtidos mostraram que a pimenta-do-reino, além do manjericão, foram os condimentos que apresentaram maior contaminação fúngica, sendo identificados oito gêneros e 246 espécies isoladas de fungos nas amostras analisadas. Elevados valores de bolores e leveduras presentes nas amostras exigem atenção pelo fato destes microrganismos serem poderosos agentes deteriorantes, acarretando transformações indesejáveis ao alimento.

\section{Coliformes totais e coliformes termotolerantes}

De acordo com os resultados obtidos nas análises referentes a coliformes totais e coliformes termotolerantes a $45^{\circ} \mathrm{C}$, as amostras indicaram a presença 
somente do grupo dos coliformes totais. A porcentagem de amostras que foram positivas para esse indicador microbiológico foi de $83,3 \%, 66,6 \%$ e $100 \%$ em amostras oriundas de feiras livres e mercado municipal; supermercados e indústria exportadora, respectivamente.

TABELA 2 - Coliformes totais com valores expressos em Número Mais Provável $\mathrm{NMP} / \mathrm{g}$ de alimento em pimenta-do-reino comercializada em São Mateus, Espírito Santo.

\begin{tabular}{cc}
\hline Amostra & Coliformes Totais (NMP/g) \\
\hline $1-$ Feiras & Feiras livres e Mercado Municipal \\
2 - Feiras & $<3,0$ \\
3 - Feiras & $1,1 \times 10^{3}$ \\
$4-$ Mercado & $1,1 \times 10^{3}$ \\
5 - Mercado & $6,3 \times 10^{3}$ \\
6 - Mercado & $3,0 \times 10^{3}$ \\
\hline 1 & $7,4 \times 10^{3}$ \\
2 & $3,0 \times 10^{3}$ \\
3 & $<3$ \\
4 & $3,6 \times 10^{3}$ \\
5 & $6,1 \times 10^{3}$ \\
6 & $<3,0$ \\
1 & $3,0 \times 10^{3}$ \\
2 & Supermercados \\
4 & $1,1 \times 10^{6}$ \\
5 & $1,1 \times 10^{6}$ \\
6 & $1,1 \times 10^{6}$ \\
& $1,1 \times 10^{6}$ \\
& $1,1 \times 10^{6}$ \\
\hline
\end{tabular}

De acordo com a ANVISA (2001) os valores permitidos para a presença de coliformes é de 4,0 × 10 $\mathrm{NMP} / \mathrm{g}$ em amostras de especiarias, de forma que apenas três amostras não apresentaram coliformes totais sendo uma amostra oriunda de feira livre e duas amostras de supermercado. Porém nenhuma das 18 amostras analisadas apresentaram contaminação por coliformes termotolerantes, o que torna as amostras de pimenta-do-reino em acordo com os padrões estabelecidos em relação aos coliformes termotolerantes.

Estudos realizados por Correia et al. (2017), verificando a qualidade microbiológica de saladas produzidas em cozinhas hospitalares no estado de São Paulo, encontraram valores elevados, expressos em número mais provável - NMP, de coliformes totais e termotolerantes, superiores a $1,1 \times 10^{3} \mathrm{NMP} / \mathrm{g}$ de alimento, mesmo quando são submetidas ao tratamento térmico, reforçando a importância do seguimento de critérios técnicos na execução das práticas sanitárias. Importante ressaltar que, por conter tubérculos em sua composição, estas saladas podem apresentar maior contaminação devido ao contato do produto com o solo durante a produção e a colheita. Silva et al. (2013) verificando as condições microbiológicas de diferentes especiarias comercializadas na feira central de Campina Grande, Paraíba, observaram que $55 \%$ das amostras de pimenta-do-reino excediam o limite de $1,1 \mathrm{x}$ 
$10^{3} \mathrm{NMP} / \mathrm{g}$ estabelecido para coliformes totais, sendo que $33 \%$ do total de amostras também excediam o limite estabelecido pela ANVISA em relação aos coliformes termotolerantes, de forma que estas amostras se encontraram fora dos padrões para comercialização e consumo.

No intuito de reduzir a contaminação por microrganismos, Aranha et al. (2017) avaliaram o desempenho da radiação gama no processo de conservação de farinhas oriundas de abacaxi, melão, mamão e maçã, obtendo redução na população microbiana, além da ausência de coliformes termotolerantes. Resultado semelhante foi obtido por Prates et al. (2017), em que foi observada ausência de coliformes termotolerantes em leite após pasteurização, além de ausência de Salmonella spp. Em concordância com a ausência de coliformes termotolerantes se encontra o trabalho de Oliveira et al. (2017) analisando diferentes especiarias comercializadas em feiras livres no município de Cuiabá, Mato Grosso, dentre estas a pimenta-do-reino que mesmo apresentando maior crescimento de colônias fúngicas, estava dentro dos padrões em relação aos coliformes termotolerantes.

É possível observar a variabilidade na ocorrência e na quantidade destes microrganismos, pelo fato de existirem diversas fontes de contaminação ao longo da cadeia produtiva, com destaque as etapas de manipulação, como observado durante a obtenção das amostras em feiras livres e mercado municipal onde não havia higienização das mãos entre a preparação do produto e a recepção das cédulas de dinheiro. Falhas ocorridas durante o beneficiamento e armazenamento podem acarretar em elevação da contaminação sendo evidenciado pelos elevados valores nas amostras provenientes da indústria exportadora.

\section{Detecção de Salmonella spp}

Os padrões microbiológicos para alimentos segundo a RDC 12/2001 da ANVISA (ANVISA, 2001) estipulam que especiarias íntegras ou moídas devem apresentar ausência de bactérias do gênero Salmonella spp. em $25 \mathrm{~g}$ de amostra. Nas análises realizadas utilizando as amostras pimenta-do-reino provenientes de feiras livres, mercado municipal, supermercados e indústria exportadora não foi identificada contaminação por esse tipo de microrganismo confirmando que estão em conformidade com os padrões estabelecidos pela legislação vigente.

Também não houve identificação de Salmonella spp. em 641 amostras de saladas produzidas em restaurantes de hospitais públicos do estado de São Paulo (CORREIA et al., 2017). Bem como nos trabalhos de Barbosa et al. (2016) comparando a qualidade microbiológica de amostras de alface comercializadas em Teresina - Piauí provenientes de duas formas de produção, convencional e hidropônico, encontrando apenas uma amostra positiva, sendo esta correspondente a produção convencional, quando há contato com o solo e mais susceptível a contaminação.

Aranha et al. (2017) também não detectaram presença de Salmonella spp. analisando farinhas obtidas a partir de resíduos de processamento de diferentes frutas numa indústria no estado de São Paulo, corroborando com os resultados deste estudo, comprovando a aptidão dos produtos à comercialização e consumo. A presença de Salmonella spp. é um indicativo da ocorrência de falhas durante o processamento e industrialização da pimenta-do-reino, pelo não seguimento das boas práticas higiênicas, responsáveis por uma eventual contaminação do produto e consequentemente risco ao consumidor, conforme afirma Michelim et al. (2016) e Prates et al. (2017). 


\section{CONCLUSÃO}

As amostras provenientes dos supermercados e da indústria exportadora apresentaram elevado número de colônias de microrganismos aeróbios mesófilos, enquanto amostras adquiridas de feiras livres, mercado municipal e supermercados apresentaram maior contaminação por bolores e leveduras.

Nenhuma das amostras analisadas apresentaram coliformes termotolerantes ou contaminação por Salmonella spp.

Faz-se necessária o aperfeiçoamento das etapas envolvidas no processo produtivo devido aos riscos à saúde do consumidor, sugerindo o cumprimento de boas práticas de produção garantindo assim a qualidade do produto até o consumidor final.

\section{REFERÊNCIAS}

ALVES, H.; ALENCAR, E. R.; FERREIRA, W.F.S.; SILVA, C.R.; RIBEIRO, J.L. Aspectos microbiológicos e físico-químicos de morango exposto ao gás ozônio em diferentes concentrações durante 0 armazenamento. Brazilian Journal of Food Technology, v.22, 2019. Disponível em: http://www.scielo.br/scielo.php?script=sci_arttext\&pid=S1981-67232019000100402\& Ing=pt\&tlng=pt DOI: 10.1590/1981-6723.00218 Acesso em: 24/08/2019

ANDRADE, C.G.C.; SILVA, M.L.; SALLES, T.T. Fatores impactantes no valor bruto da produção de pimenta-do-reino (Piper nigrum L.) no Pará. Floresta e Ambiente, v.24, $2017 . \quad$ Disponível em: http://www.scielo.br/scielo.php?script=sci_arttext\&pid=S2179-80872017000100186\& Ing=pt\&tIng=pt DOI: 10.1590/2179-8087.145615

ANVISA - Agência Nacional de Vigilância Sanitária. Regulamento Técnico sobre os padrões microbiológicos para alimentos, 2001. Disponível em: http://portal.anvisa.gov.br/documents/33916/0/Resolu\%C3\%A7\%C3\%A30+RDC+n\% $\mathrm{C} 2 \% \mathrm{BA}+12 \% 2 \mathrm{C}+\mathrm{de}+02+\mathrm{de}+$ janeiro+de+2001/0fa7518b-92ff-4616-85e9bf48a6a82b48?version $=1.0$

APHA - AMERICAN PUBLIC HEALTH ASSOCIATION. Compendium of methods for the microbiological examination of foods. 4th ed, 2001. $676 \mathrm{p}$.

ARANHA, J.B.; NEGRI, T.C.; MARTIN, J.G.P.; SPOTO, M.H.F Efeito da radiação gama nos parâmetros microbiológicos, físico-químicos e compostos fenólicos de farinha de resíduos de frutas durante armazenamento. Brazilian Journal of Food Technology, V.20, 2017. Disponível em: http://www.scielo.br/pdf/bjtt/v20/1981-6723bjft-20-e2016123.pdf DOI: 10.1590/1981-6723.12316 Acesso em: 26/08/2019

BARBOSA, V.A.A.; CARDOSO FILHO, F.C.; SILVA, A.X.L.; OLIVEIRA, D.G.S.; ALBUQERQUE, W.F.; BARROS, V.C. Comparação da contaminação de alface (Lactuca sativa) proveniente de dois tipos de cultivo. Revista Brasileira de Higiene e Sanidade Animal, v.10, n.2, p.231-242, 2016. Disponível em: http://www.higieneanimal.ufc.br/seer/index.php/higieneanimal/article/view/315 DOI: 10.5935/1981-2965.20160020 Acesso em: 27/08/2019 
CARNEIRO JUNIOR, J.F.C.; LIMA, J.M.; SILVA, A.L.P.; NASCIMENTO, M.N.C.F. Análise de mercado da pimenta do reino no período de 1990 a 2015. Revista Tecnologia \& Ciência Agropecuária, v.11, n.6, p.139-145, 2017. Disponível em: http://revistatca.pb.gov.br/edicoes/volume-11-2017/v-11-n-6-dezembro-2017/19artigo-ce-0817-05-analise-de-mercado-da-pimenta-do-reino.pdf Acesso em: $24 / 08 / 2019$

CORREIA, L.B.N.; POSSEBON, F.S.; YAMATOGI, R.S.; PANTOJA, J.C.F.; MARTINS, O.A.; AMARAL, G.P.; BIONDI, G.F. Microbiological profile of diferente types of salads from hospital kitchens. Arquivos do Instituto Biológico, v.84, p.1-7, 2017. Disponível em: http://www.scielo.br/scielo.php?script=sci_arttext\&pid=S1808-

16572017000100213 DOI: 10.1590/1808-1657000792015 Acesso em: 26/08/2019.

FRANCO, B.D.G.M.; LANDGRAF, M. Microbiologia dos Alimentos. Atheneu, São Paulo, 2008. 182p

LIMA, E.N.S.; MENDES, R.A.; AMARAL, A.B.; CARRIJO, K.F. Análise microbiológica de saladas e águas servidas em um restaurante universitário do Triângulo Mineiro, Minas Gerais, Brasil. Enciclopédia Biosfera, v.11, n.22, p.3176-3185, 2015. Disponível em: http://www.conhecer.org.br/enciclop/2015c/saude/analise\%20microbiologica.pdf DOI: 10.18677/Enciclopedia_Biosfera_2015_033

MICHELIN, A.F.; ARAUJO, M.J.; KIMURA, R.S.; BRONHARO, T.M. Contaminação por enteropatógenos em pimenta-do-reino moída. Instituto Adolfo Lutz, v.26, p.1-3, 2016. Disponível em: http://www.ial.sp.gov.br/resources/insituto-adolfolutz/publicacoes/bial/bial_26/26u_art-1.pdf Acesso em: 27/08/2019

OLIVEIRA, A.P.; ARRUDA, G.L.; PEDRO, F.G.G.; OLIVEIRA, J.C.; HAHN, R.; TAKAHARA, D. Contaminação fúngicas em especiarias desidratadas comercializadas no Mercado do Porto de Cuiabá-MT. Brazilian Journal of Food Research, v.7, n.1, p.149-160, 2016. Disponível em: https://periodicos.utfpr.edu.br/rebrapa/article/download/3523/pdf_1 Acesso em: $24 / 08 / 2019$

OLIVEIRA, J.O.; VILELA, L.T.O.; SILVA, L.H.O.; NASCIMENTO, T.S.; MAGALHÃES, F.A.C.; VIVI, V.K. Análise microbiológica de especiarias desidratadas comercializadas em feiras livres em Cuiabá, Mato Grosso. Journal Health, v.2, n.2, p.365-379, 2017. Disponível em: https://periodicos.unemat.br/index.php/jhnpeps/article/view/2572 Acesso em: $24 / 08 / 2019$

OLIVEIRA, M.G.; OLIOSI, G.; PARTELLI, F.L.; RAMALHO, J.C. Physiological responses of photosynthesis in black pepper plants under different shade levels promoted by intercropping with rubber trees. Ciência e Agrotecnologia, v.42, n.5, 
p.513-526, 2018. Disponível em: http://www.scielo.br/scielo.php?script=sci_arttext\& pid=S1413-70542018000500513\&tIng=en DOI: 10.1590/1413-70542018425020418 Acesso em: 24/08/2019

PRATES, D.F.; WÜRFEL, S.R.; GOLDBECK, J.C.; LIMA, A.S.; LOPES, G.V.; SILVA, W.P. Microbiological quality and safety assessment in the production of moderate and high humidity chesses. Ciência Rural, v.47, n.11, 2017. Disponível em: http://www.scielo.br/pdf/cr/v47n11/1678-4596-cr-47-11-e20170363.pdf DOI: 10.1590/0103-8478cr20170363 Acesso em: 26/08/2019

SANTOS, E.H.F.; NETO, A.F.; DONZELI, V.P. Aspectos físico-químicos e microbiológicos de polpas de frutas comercializadas em Petrolina - PE e Juazeiro BA. Brazilian Journal of Food Technology, v.19, 2016. Disponível em: http://www.scielo.br/pdf/bjft/v19/1981-6723-bjft-1981-67238915.pdf DOI: 10.1590/1981-6723.8915 Acesso em: 25/08/2019

SILVA, J.F.; MELO, B.A.; LEITE, D.T.; CORDEIRO, M.F.R.; PESSOA, E.B.; BARRETO, C.F.; FERREIRA, T.C. Análise microbiológica de condimentos comercializados na feira central de Campina Grande - PB. Agropecuária Científica no Semi-Árido, v.9, n.2, p.83-87, 2013. Disponível em: http://revistas.ufcg.edu.br/acsa/index.php/ACSA/article/view/370 DOI: 10.30969/acsa.v9i2.370 Acesso em: 26/08/2019

SILVA, N.; JUNQUEIRA, V. C. A.; SILVEIRA, N. F. A.; TANIWAKI, M. H.; SANTOS, R. F. S.; GOMES, R. A. R. Manual de métodos de análise microbiológica de alimentos e água. Varela, São Paulo, 4 ed, 2010. 535p. Disponível em: https://books.google.com.br/books?hl=pt-BR\&lr=\&id=ki9dDwAAQBAJ\&oi=fnd\&pg= PA88\&ots=QSKFC5lzmY\&sig=JcpPyAz28qqXbNz2Bk9nAjv37SA\&redir_esC=y\#v=on epage \&q\&f=false Acesso em: 06/11/2019

SILVA, R.F.; BUENO, A.C.; RAMOS, P.J.R.B.; ORLANDI, R.D.M.; BORGES, M.T.B.R, MEDEIROS, S.D.S.; CECCATO-ANTONINI, S.R.; MARTIN, J.G.P.; SPOTO, M.H.F.; VERUMA-BERNARDI, M.R. Avaliação da qualidade de açúcares mascavado. Revista de Ciências Agrárias, v.41, n.4, p.1098-1106. 2018. Disponível em: https://revistas.rcaap.pt/index.php/rca/article/view/16787 DOI: 10.19084/RCA18077 Acesso em: 25/08/2019

SOARES, K.; MORAIS, D.; GÓIS, V.; SILVA, J.; COSTA, A.; SILVA, L. Quality of unprocessed cooled fresh coconut water manually extracted by street vendors. Food Safety, v.84, p.1-5, 2017. Disponível em: http://www.scielo.br/pdf/aib/v84/1808-1657-

aib-84-e0512016.pdf DOI: 10.1590/1808-1657000512016 Acesso em: 25/08/2019

SONG, W-J.; SUNG, H-J.; KIM, S-Y.; KIM, K-P.; RYU, S.; KANG, D-H. Inactivation of Escherichia coli 0157:h7 and Salmonella Typhimurium in black pepper and red pepper by gamma irradiation. International Journal of Food Microbiology, v.172, 
p.125-129,

2014.

Disponível

em:

https://www.sciencedirect.com/science/article/abs/pii/S0168160513005382?via\%3Di

hub DOI: 10.1016/j.ijfoodmicro.2013.11.017 Acesso em: 24/08/2019

SOUZA, G.C.; SANTOS, C.T.B.; ANDRADE, A.A.; ALVES, L. Comida de rua: avaliação das condições higiênico-sanitárias de manipuladores de alimentos. Ciência \& Saúde Coletiva, v.20, n.8, p.2329-2338, 2015. Disponível em: http://www.scielo.br/scielo.php?script=sci_arttext\&pid=S1413-81232015000802329

DOI: 10.1590/1413-81232015208.14922014 Acesso em: 25/08/2019

TRINDADE, S.N.C.; PINHEIRO, J.S.; ALMEIDA, H.G.; PEREIRA, K.C.; COSTA SOBRINHO, P.S. Bacteriological quality and food safety in a Brazilian school food program. Nutrición Hospitalaria, v.29, n.1, p.80-87, 2014. Disponível em: http://scielo.isciii.es/pdf/nh/v29n1/11 original5.pdf DOI: 10.3305/nh.2014.29.1.7006 Acesso em 25/08/2019

WEBBER, B.; OLIVEIRA, A.P.; POTTKER, E. S.; DAROIT, L.; LEVANDOWSKI, R.; SANTOS, L.R.; NASCIMENTO, V.P.; RODRIGUES, L.B. Salmonella enteritidis forms biofilm onder low temperatures on different food industry surfaces. Ciência Rural, v.49, n.7, 2019. Disponível em: http://www.scielo.br/scielo.php?script=sci_arttext\&pid=S0103-

84782019000700452\&tIng=en DOI: 10.1590/0103-8478cr20181022 Acesso em: $24 / 08 / 2019$ 